Published in final edited form as:

Pediatr Exerc Sci. 2009 May ; 21(2): 171-185.

\title{
Modifying Middle School Physical Education: Piloting Strategies to Increase Physical Activity
}

\author{
Russell Jago, Robert G. McMurray, Stanley Bassin, Laura Pyle, Steve Bruecker, John M. \\ Jakicic, Esther Moe, Tinker Murray, and Stella L. Volpe \\ Jago is with the Department of Exercise, Nutrition \& Health Sciences, University of Bristol, UK. \\ McMurray is with the Department of Exercise and Sport Science, University of North Carolina, \\ Chapel Hill, NC. Bassin is with the Division of Cardiology, Preventive Cardiology Program, University \\ of California, Irvine, CA. Pyle is with the George Washington University Biostatistics Center, \\ Washington, DC. Bruecker is with the University of California, Irvine, CA. Jakicic is with the Physical \\ Activity and Weight Management Research Center, University of Pittsburgh, Pittsburgh, PA. Moe \\ is with the Division of Health Promotion and Sports Medicine, Oregon Health \& Science University, \\ Portland, OR. Murray is with the Department of Health Physical Education and Recreation, Texas \\ State University, San Marcos, TX. Volpe is with the Division of Biobehavioral and Health Sciences, \\ University of Pennsylvania, Philadelphia, PA
}

\begin{abstract}
Two pilot studies were conducted to examine whether 6th grade students can achieve moderate to vigorous physical activity (MVPA) from 1) activity-based physical education (AB-PE) with 585 participants and 2) a curricular-based (CB-PE) program with 1,544 participants and randomly sampled heart rates during lessons. AB-PE participants spent between 54-66\% with a heart rate $>140$ bpm. CB-PE participants spent between $49-58 \%$ with a heart rate $>140 \mathrm{bpm}$. Girls' mean heart rate was 3.7 bpm lower than the boys. PE can be readily modified so that students spend more than $50 \%$ of time in MVPA.
\end{abstract}

\section{Background}

Regular physical activity is associated with a decreased risk of type 2 diabetes mellitus (15), cardiovascular disease (13) and some cancers (21) among adults. Moderate to vigorous intensity physical activity (MVPA) has been associated with improved glycemic status (27), lipid levels (20) and lower BMI (17) among youth. A number of health-related organizations have provided physical activity recommendations for youth. While the recommended amount

(C) 2009 Human Kinetics, Inc.

The following individuals and institutions constitute the STOPP-T2D Prevention Study Group (* indicates principal investigator or director): STOPP-T2D Study Chair Children's Hospital Los Angeles: F.R. Kaufman Field Centers Baylor College of Medicine: T. Baranowski*, L. Adams, J. Baranowski, A. Canada, K.T. Carter, K.W. Cullen, M.H. Dobbins, R. Jago, A. Oceguera, A.X. Rodriguez, C. Speich, L.T. Tatum, D. Thompson, M.A. White, C.G. Williams Oregon Health \& Science University: L. Goldberg*, D. Cusimano, L. DeBar, D. Elliot, H.M. Grund, S. McCormick, E. Moe, J.B. Roullet, D. Stadler Temple University: G. Foster* (Steering Committee Chair), J. Brown, B. Creighton, M. Faith, E.G. Ford, H. Glick, S. Kumanyika, J. Nachmani, L. Rosen, S. Sherman, S. Solomon, A. Virus, S. Volpe, S. Willi University of California at Irvine: D. Cooper*, S. Bassin, S. Bruecker, D. Ford, P. Galassetti, S. Greenfield, J. Hartstein, M. Krause, N. Opgrand, Y. Rodriguez, M. Schneider University of North Carolina at Chapel Hill: J. Harrell*, A. Anderson, T. Blackshear, J. Buse, J. Caveness, A. Gerstel, C. Giles, A. Hackney, A. Jessup, P. Kennel, R. McMurray, D. Rubin, A-M. Siega-Riz, M. Smith, A. Steckler, A. Zeveloff University of Pittsburgh: M.D. Marcus*, M. Carter, S. Clayton, B. Gillis, K. Hindes, J. Jakicic, R. Meehan, R. Noll, J. Vanucci, E. Venditti University of Texas Health Science Center at San Antonio: R. Treviño*, A. Garcia, D. Hale, A. Hernandez, I. Hernandez, C. Mobley, T. Murray, J. Stavinoha, K. Surapiboonchai, Z. Yin Coordinating Center George Washington University: K. Hirst*, K. Drews, S. Edelstein, L. El ghormli, S. Firrell, M. Huang, P. Kolinjivadi, S. Mazzuto, T. Pham, A. Wheeler Project Office National Institute of Diabetes and Digestive and Kidney Diseases: B. Linder*, C. Hunter, M. Staten Central Blood Laboratory University of Washington Northwest Lipid Metabolism and Diabetes Research Laboratories: S.M. Marcovina* 
of activity has varied from between 30 (32) and 60 min of physical activity per day $(5,30)$, recent evidence suggests that many adolescents do not obtain $30 \mathrm{~min}$ of moderate to vigorous activity per day (16). Physical Education (PE) provides a venue and an opportunity, in which all children who attend school may be physically active. Moreover, an accelerometer-based study found that $3 \mathrm{rd}$ and 4 th grade students were more active in the after-school period on days when they had outdoor recess and PE than when these opportunities were deprived (4).

Although, it is not clear what the exact mechanism for this difference was the findings suggest that activity during school time might encourage students to be more active outside of school. Unfortunately, due to funding limitations and societal pressure to raise the standards in core subjects such as math and English, curriculum time allocated to PE and the enrollment in PE lessons has reduced (7). While PE has many well established objectives such as the development of sport skills, sport knowledge, teamwork and social skills, it also provides significant opportunities for regular MVPA. PE can therefore help youth meet established physical activity guidelines.

International evidence indicates that the level of activity that is obtained during PE classes is relatively low. Observational data indicate that 3rd grade students in the United States (US) spent only $36 \%$ of their PE lessons engaged in moderate to vigorous intensity physical activity (MVPA; 24 ) with a similar proportion (35\%) reported among Australian students (33). A recent paper from the US Trial for Activity in Adolescent Girls (TAAG) study group, (which also used the same observational instrument as the studies listed above), reported that 6th grade girls spent an average of $37.9 \%$ of PE classes engaged in MVPA (23). Similarly, heart rate monitoring of activity in PE lessons in the United Kingdom (UK) indicated that 11-14 year old students spent an average of $34 \%$ of the lesson engaged in MVPA (11). It should be noted however, that although the findings are consistent across studies, the definition of MVPA has varied. The observational studies have used the System for Observing Physical Activity Instruction Time (SOFIT) which categorizes walking as moderate intensity physical activity (25). The UK study employed heart rate monitoring and an estimate of MVPA that was based on the participants resting heart rate. These methods were likely selected to assess different dimensions of physical activity because heart rate monitoring provides a better indication of the cardiovascular load of an activity, while the observational methods provide a more behavioral indication of the type of activity that takes place during the class (10). Alternative definitions will likely lead to different interpretations of the amount of activity that participants obtain from PE classes.

The data presented above suggest that many children are not meeting the US Department of Health and Human Services (DHHS) Healthy People 2010 target of adolescents spending "at least 50 percent of school PE class time being physically active" (31). Research conducted in elementary schools indicates that providing new curriculum materials and training can result in increased MVPA during PE classes (33). However, with the exception of one published intervention (26) and the TAAG investigation that specifically focused on girls (23), there has been little research conducted in U.S. middle schools on the value of additional training and supplies.

The data reported here are the results of preliminary work that were conducted by the Studies to Treat or Prevent Pediatric Type 2 Diabetes (STOPP-T2D) - Prevention study group in 2003 and 2004. STOPP-T2D-Prevention is a multisite study funded by the National Institute of Diabetes and Digestive and Kidney Diseases that is designed to reduce the risk factors for type 2 diabetes among middle school children. Two studies were conducted sequentially to address two objectives. The aim of the first study (the activity study) was to examine the upper limit of MVPA that can be obtained during regularly scheduled US middle school PE classes, this would provide an indication of the maximum amount of activity that could be achieved. The aim of the second study (the curriculum study), was to determine the amount of MVPA that 
can be obtained while meeting state mandated curriculum guidelines. The second study was designed to provide information about the maximum amount of physical activity that could realistically be obtained and maintained over time in US middle schools while also addressing the broader PE objectives of skill development, knowledge teamwork and facilitating lifelong physical activity. A further aim of both studies was to ascertain how the interpretation of the amount of activity obtained from PE classes differs according to the definition of MVPA.

\section{Activity-Based Study}

\section{Methods}

The 2003 activity-based study was conducted at three field centers located in Texas (Baylor College of Medicine, Houston TX), California (University of California Irvine, Irvine CA) and North Carolina (University of North Carolina at Chapel Hill, Chapel Hill NC), with George Washington University Biostatistics Center, Washington DC as the coordinating center. Each school recruited 2 coeducational middle schools in which at least $40 \%$ of the students enrolled at the school were from an ethnic minority known to be at increased risk for type 2 diabetes mellitus (African American, Native American or Hispanic).

Students were recruited from classes that were mostly comprised of 6th grade students and that were taught by a specialist PE teacher who consented to take part in the intervention. Written parental consent and childhood assent were obtained for data collection. Students received \$5 each time that they wore a heart rate monitor. The Institutional Review Boards of all the participating sites approved this study.

The study was designed to test the feasibility of using specific activities to increase the amount of MVPA that could be obtained from activity-based PE classes. Before study implementation the STOPP-T2D Physical Activity Intervention Committee in consultation with three US middle school PE experts compiled 56 instruction cards for activities that could be combined to create a lesson plan and taught to multiple small groups at a time. Example activities included chase games, activity based circuit activities such as an athletics steeplechase, and skill building drills such as a basketball knock-out drill in which students attempt to retain ball possession while also "knocking" another students ball out of the court. All the activities were designed to result in high levels of MVPA and were taught by the regular PE teacher. The Fitness Laboratory On Wheels (FLOW), an enjoyment-oriented circuit-training program, which focused on personal challenge and exercising to music was also used (Scott Bowman, Rancho Middle School, Orange County, CA). A Teaching Assistant (TA) who possessed a sport-related degree was hired to work in each of the sixth grade classes. The TAs assisted with the class instructions, motivation, supervision, and class management. By performing these tasks, the TA reduced the amount of time that the PE teachers spent on equipment set-up and basic administration, thereby increasing the time available for physical activity.

Each field center hired a "Master PE Teacher" who had extensive middle school PE teaching experience, mentoring experience and was recognized by their school district as an exemplary teacher. The Master PE Teachers attended a five-day central training in which they were familiarized with the study and taught how to implement FLOW and the activity cards. The Master PE Teachers also received training in classroom management techniques, such as forming small groups quickly, effective supervision of small groups, providing succinct instructions, recording attendance quickly and positive reinforcement. Although the Master PE teachers all had extensive expertise in these areas, they were all from different states and had been in different teaching environments. Therefore, to ensure program fidelity it was important to provide a uniform Master PE teacher training on these fundamental pedagogical skills to enable consistent training at each field center. 
After the Master PE teachers had attended central training, they implemented a two-day (16hr) training program for two PE teachers, all of whom were curriculum specialists, and the TA at each of the respective local schools. The local PE teacher training focused on classroom management skills, grouping strategies, active supervision, concise instructional cues, working with a teaching assistant, social skills, and strategies for teaching motor skills without sacrificing MVPA during the lesson. Each school received all of the equipment necessary to implement the redesigned activities (approximate value $\$ 10,000$ ). (The equipment was primarily sufficient amounts of balls, cones and pennies to ensure that each student could engage in the activities, i.e., one ball per student). After local training, the school teachers and their TAs were given two weeks to familiarize themselves with the study materials and practice (with support from the Master PE Teacher), all aspects of the program. Once this phase had been completed, the PE teachers were instructed to implement the study lessons over the next seven weeks and data collection began. The scheduled class length was $45 \mathrm{~min}$ at five of the intervention schools and $90 \mathrm{~min}$ at the other school.

Five students for whom parental consent and childhood assent had been obtained were randomly selected to wear heart rate monitors (Polar Pacer E600, Polar Electro, Lake Success, NY) during each 6th grade PE class in which data were collected. As the assessment was focused on the physical activity levels of the class and not the individual students' different students wore the monitors in each lesson. The lesson frequency differed between schools with some schools scheduling daily PE while other schools were on a block schedule in which PE was taught in 90 min periods every other day. Thus, the number of wear opportunities differed by school. However, to minimize the potential for any very keen participants to skew the data no student wore a heart rate monitor more than eight times, with the median number of wear occasions being 3 times per child. However, if a student wore the monitor more than once, the data were treated as repeated measures. The monitors were placed on the students as soon as they left the locker room at the start of each class, and removed when the teacher signaled the end of the lesson. Monitors were intended to be programmed to record heart rates at five-second intervals; however, as a result of a technical error, data for the first two weeks were collected at one-minute intervals. To minimize participant and school burden, demographic and anthropometric data were not collected because the 2003 study was focused on the upper limit of activity that could be obtained and not gender or BMI differences in activity.

\section{Data Coding and Preparation}

Data were cleaned before analysis. Heart rate values were set to missing if $<50$ or $>215$ beats per minute (bpm), or if the average bpm for consecutive 1 min intervals dropped by $>45 \%$ or increased by $>80 \%$. Records collected from heart rate monitors were excluded if more than $75 \%$ of the data that should have been collected during the class period were missing. As some of the activity study heart rate data were collected in 1 min intervals instead of 5-second intervals, data that were collected in 5-second intervals were averaged into 1 min intervals.

Although heart rate monitoring facilitates an assessment of the physiological demand of the activity on the participant, interpreting heart rate data are problematic as many different interpretations of the heart rate threshold that is equivalent to moderate to vigorous physical activity have been employed (9). Cut-point thresholds of minutes above $120 \mathrm{bpm}$ (6) and 140 bpm (17) have been frequently used among children and adolescents. Other investigators have employed manipulations of the participant's heart rate reserve which takes account of the participant's resting and maximal heart rates (11). Adult-based research has shown that physical activity that is at least equivalent to $40 \%$ of maximal capacity is necessary to influence fasting insulin levels (3). Kang and colleagues (19) have shown that physical activity that is at least $55 \%$ of maximal capacity can result in improvements in lipid levels and blood pressure among obese adolescents. Thus, in the absence of early adolescent specific thresholds we wanted to 
ascertain the amount of time that students spent engaged in activity that was at least equivalent to $40 \%$ of maximal capacity (heart rate $\geq 130 \mathrm{Bpm}$ ) while also examining the time spent engaged in activity that was equivalent to $55 \%$ of maximal capacity (heart rate $\geq 140 \mathrm{Bpm}$ ). These two thresholds were interpreted as the low (heart rate $\geq 130$ ) and middle (heart rate $\geq 140 \mathrm{bpm}$ ) ranges of MVPA and are consistent with the values used in the literature $(1,6,17)$. We also calculated the mean heart rate for each session to provide a description of the average intensity of the session.

\section{Statistical Analyses}

Means and standard deviations for each outcome variable were computed by week of the intervention. Continuous outcome variables (mean bpm, percent of class with a HR $>130 \mathrm{bpm}$ and a HR > $140 \mathrm{bpm}$ ) were regressed against the duration of the intervention to determine if the time spent engaged in activity increased as a function of time. Linear regression models fitted to the relationship between minutes of MVPA with class length indicated that the minutes of MVPA obtained was positively correlated with class length $(p<.0001)$. As a result, the minutes above each of the thresholds were expressed as a percentage of the time that the monitors were worn. The models were general linear mixed models (GLMM) with school as a random effect to account for the correlation expected among students within a school (22). Although some participants provided data more than once we used a random number table to obtain five participants in each class and the groups of five participants were always different. However, if a student wore the monitor more than once, the data were treated as repeated measures. All analyses were conducted using Statistical Analyses Software (SAS) version 9.1 (SAS Institute Inc, Cary NC).

\section{Results}

There were 585 students who provided consent for the study. The mean heart rate and the mean percent of class time spent with a heart rate above 130 and $140 \mathrm{bpm}$ for each of the seven weeks for which data were collected are reported in Table 1. The mean heart rate ranged from 143 to $150 \mathrm{bpm}$ while the percent of monitored class time spent with a heart rate above 130 and 140 bpm ranged from $66 \%$ to $76 \%$ and $55-66 \%$ respectively. Analysis of the data indicated that the mean heart rate increased by an average of $0.2 \mathrm{bpm}(95 \%$ confidence interval $(\mathrm{CI})=0.1-0.3$, $p<.0001$ ) for each day of the intervention. The percent of time spent engaged in activity that produced a heart rate $>130 \mathrm{bpm}$ increased by $0.3 \%$ per day $(95 \% \mathrm{CI}=0.2-0.4, p<.0001)$, while the percent time with a heart rate $>140 \mathrm{bpm}$ increased by $0.3 \%$ per day $(95 \% \mathrm{CI}=0.2-0.4$, $p<.0001$ ) of the study.

\section{Discussion}

In this study we obtained an average of $58.7 \%$ of the class with a heart rate above $140 \mathrm{bpm}$ excluding the time spent changing at the beginning and end of the lesson. This was approximately equivalent to 16 min of physical activity in a 45 -min class that includes changing time. Comparison with other studies is difficult because there is a lack of contemporary data from U.S. middle schools that has employed heart rate monitoring approaches. Our findings are, however, similar to an earlier middle school study that reported a mean of 19 min of MVPA following an intervention (26). The $19 \mathrm{~min}$ of MVPA reported in the earlier study were based on an observed MVPA category that included both walking and vigorous activity (26). Since the cut-point of minutes $>140 \mathrm{bpm}$ does not include lower intensity activity such as walking, the amount of activity obtained in our study is likely to be at least comparable, if not greater. The data therefore suggest that the average amount of activity that was obtained from modified PE classes that included changing was $38.4 \%$ of total class time if a $140 \mathrm{bpm}$ heart rate is used or $45.9 \%$ of total class time if a $130 \mathrm{bpm}$ heart rate definition is used to indicate MVPA. It 
should be noted, however, that some classes, with highly motivated teachers who were able to quickly transition their students from one activity to the next were able to attain 36-38 min of MVPA in a 45-min class.

The amount of physical activity obtained increased with exposure to the intervention. For example, the mean heart rate obtained during the study increased from $144 \mathrm{bpm}$ in week one to $150 \mathrm{bpm}$ in week seven. Similarly, the percent of time engaged in activity with a heart rate above $140 \mathrm{bpm}$ increased from $~ 55 \%$ in week one to $64 \%$ in week seven. The weekly increases in mean heart rate and minutes of MVPA suggest that the PE teachers were learning how to deliver the new activities, how to reduce nonactive class time, and improve their ability to increase MVPA. This implies that the program was able to yield the desired change in activity, but the changes took time to have an effect. This finding is consistent with the Middle School Physical Activity and Nutrition (MSPAN) study that reported cumulative increases in MVPA in PE during a 2 year intervention (26). Collectively, these findings suggest that changes to middle school PE can be made, but changes may take time to "bed in" while the teachers learn and implement the new classroom management methods.

\section{Curriculum-Based Study}

\section{Methods}

The three original field centers and the coordinating center were joined by four additional field centers in Oregon (Oregon Health \& Sciences University), Pittsburgh (University of Pittsburgh), Philadelphia (University of Pennsylvania) and San Antonio (University of Texas Health Science Center-San Antonio) for the 2004 curriculum based study. Each of the seven field centers recruited one coeducational middle school using the same inclusions criteria as those employed in the 2003 study. Students received a one time payment of $\$ 25$ for participating in the PE and school food service data collection in 2004. The Institutional Review Boards of all the participating sites approved this study.

\section{Design}

The 2004 study tested more activities but also added additional elements to provide a complete curriculum. The curriculum study built on the results of the activity based study and was designed to identify the maximum amount of physical activity that could be obtained from PE classes while meeting the California, North Carolina, Oregon, Pennsylvania and Texas, state mandated curriculum requirements that focus on skill progression, teamwork and the development of lifestyle physical activity habits. Five units (Basketball, Frisbee, Jump-Rope, Soccer and Team Handball) were developed for 6th grade classes. Each unit included 8-12 lesson plans that were designed to develop student skills and knowledge in each activity. The lesson plans were a combination of the activities used in the activity based study and skillbased activities that were based on the high skills progression teaching strategy. High skills progression is a teaching approach based on the methods developed in the Sport, Play \& Active Recreation for Kids (SPARK) study that focuses on using a series of small group activities that progressively build to develop sport specific skills with each activity also including high levels of physical activity (28). The lesson plans were developed by the STOPP-T2D Physical Activity Intervention Committee.

Each site hired a Master PE Teacher who delivered a centrally developed training program that was a modification of the 2003 program to all 6th grade PE teachers in the intervention schools. The modifications included more hands-on experience with each of the lesson plans; more time spent modeling lessons, and time was devoted to reducing changing time by highlighting likely problems and quick and easy solutions to those problems. Time was also spent on demonstrating how to use the TA to maximize the amount of activity obtained from the class. 
As in the activity based study, each school also received a TA and approximately $\$ 10,000$ of PE equipment. Specialist PE Teachers and their respective assistant were then given two weeks to familiarize themselves with the study materials (with support from the Master PE Teacher). The 2004 middle school PE class length ranged from 35 to $90 \mathrm{~min}$.

\section{Measures}

The program commenced at the beginning of the school semester with local teacher training. This approach facilitated the instigation of the program before the students developed "bad habits" in relation to changing time, or the teacher's instigated management polices such as seated roll call that limited MVPA opportunities. As per the 2003 study, five students for whom parental consent and childhood assent had been obtained were randomly selected to wear heart rate monitors in each session with the median number of times that a child wore a monitor being twice. Data were cleaned using the 2003 procedures. Participant gender and ethnicity was obtained by student self-report. Height was measured to the nearest $0.1 \mathrm{~cm}$ on a stadiometer (PE-AIM-101, Perspective Enterprises, Kalamazoo, MI) with the participants shoeless and the head in the Frankfort plane. Body mass was measured to the nearest $0.1 \mathrm{~kg}$ using a precalibrated electronic scale (SECA Alpha 882, Vogel \& Halke, Hamburg). Body mass index (BMI) was calculated $\left(\mathrm{kg} / \mathrm{m}^{2}\right)$ and BMI percentile obtained using Centers for Disease Control and Prevention (CDC) age and gender specific percentiles.

\section{Statistical Analyses}

Participants were categorized as normal-weight (BMI $<85$ th percentile) or at risk for overweight (BMI $\geq 85$ th percentile). The same linear regression procedures as those applied to the 2003 were then used to analyze the data with the addition of gender, BMI group and ethnicity as covariates. All analyses were conducted using Statistical Analyses Software (SAS) version 9.1 (SAS Institute Inc, Cary NC).

\section{Results}

Descriptive statistics for the 1544 participants who provided consent for the curriculum based study are shown in Table 2 . The sample was $51 \%$ male with $46 \%$ of the participants being classified as either at risk for overweight or overweight (BMI $\geq 85$ th \%tile). The sample was 51\% Hispanic, 27\% African American and 12\% Euro-American.

Mean heart rate and mean percent of the class time with a heart rate above 130 and $140 \mathrm{bpm}$ for each week of the study is shown in Table 3 . The mean heart rate ranged from $140 \mathrm{bpm}$ in week three to $146 \mathrm{bpm}$ in week eight. Similarly, the mean percentage of the class time with a heart rate above $130 \mathrm{bpm}$ ranged from $63 \%$ in week three to $72 \%$ in week eight. The percent time spent with a heart rate above $140 \mathrm{bpm}$ ranged from $49 \%$ in week three to $58 \%$ in week one. There was no significant time effect for any of these measures $(p>.05)$.

Mean heart rate and mean percent of the class time with a heart rate above $130 \mathrm{bpm}$ and 140 bpm for each week of the study are shown separately by gender shown in Table 4. On average, the girls' mean heart rate was $3.7 \mathrm{bpm}$ lower than the boys $(95 \% \mathrm{CI}=-5.5$ to $-1.8, p=.0001$ ). Also for the girls, the percent of time with a heart rate above $130 \mathrm{bpm}$ was $4.9 \%$ lower $(95 \%$ $\mathrm{CI}=-7.8$ to $-1.9, p=.0013$ ) for the girls while the percent of time above $140 \mathrm{bpm}$ was also $6.5 \%$ lower

\section{Discussion}

The mean percent of the class (excluding changing time) that was spent engaged in physical activity was $67.1 \%$ based on minutes $>130 \mathrm{bpm}$ or $53.2 \%$ when a $140 \mathrm{bpm}$ definition was 
employed. Thus, the amount of MVPA obtained was less as a percentage of monitored class time (excluding changing time) than the levels obtained in the 2003 study but still relatively high. When examined in relation to the overall class length, however, the data indicated that we were able to obtain $23(>130 \mathrm{bpm})$ or $18(>140 \mathrm{bpm})$ minutes of a standard PE class engaged in physical activity after allowing for changing time (minutes to dress out at the beginning and end of the class). The results therefore indicated that although the amount of activity obtained in the time available decreased with the addition of the skill building activities the intervention also resulted in an overall increase in the time available by reducing changing time. The reduction in changing time was achieved by setting strict limits on changing times, playing music during changing times, and by informing the students that they needed to be changed by the end of the song. The reduction in changing time was also linked to the new curriculum since each lesson began with an enjoyable "instant activity" in which the students wanted to take part. These results show that it is possible to deliver PE lessons that meet state curriculum requirements while also ensuring that students obtain a substantial amount of health enhancing physical activity. Increased exposure to the intervention did not result in increased physical activity. The absence of a time related increase in activity in the curriculum based study suggests that our modified training program, which included more hands-on experience and modeling of activities than in the activity based study, reduced the time necessary to become familiarized with the program and could be consistently delivered after training.

The class time spent engaged in MVPA was lower for the girls than the boys. As the mean heart rates associated with the percentage of maximal effort have been shown not to vary by gender (8) these results suggest that the intervention resulted in slightly more intense activity among the boys than the girls. Our results are therefore consistent with the MSPAN study which reported that a middle school PE intervention achieved greater increases in physical activity levels for boys compared with girls (26). Since girls' habitual physical activity levels are lower than boys (16), these results indicate a need to develop more effective instructional and motivational methods of increasing the amount of activity that girls obtain from PE classes. This might be achieved by introducing activities that are more suitable and enjoyable for girls or even gender specific classes.

The amount of physical activity obtained from the classes did not differ by BMI group or ethnicity, indicating that when given the opportunity, in an activity and fun based program overweight adolescents will participate in physical activity programs as well as others. In light of the burgeoning increase in childhood obesity (14) and the potential for increased physical activity to act as a means of obesity prevention, the results of our studies suggest that modifying $\mathrm{PE}$ lessons is an effective means of increasing physical activity levels among all youth, including overweight or at risk for overweight youth.

\section{General Discussion}

The data obtained from these two pilot studies indicate that a physical education program that includes the provision of equipment, staff training, a teaching assistant and an up-dated curriculum can be successfully implemented in U.S. middle schools to ensure that participants spend at least $50 \%$ of the class engaged in MVPA. These findings are consistent with SPARK elementary school program and the MSPAN middle school intervention which both resulted in increased physical activity during PE lessons $(26,29)$. It is important to highlight that the 2004 curriculum-based study built on the findings of the work we conducted in the 2003 activity-based study to maintain high levels of physical activity while also meeting the state mandated guidelines for skill development and the development of lifelong physical activity behaviors. 
These two pilot studies were formative work in the development of a multi-component intervention to prevent type 2 diabetes mellitus among middle school students. The amount of physical activity necessary to prevent the development of insulin resistance, a key process in the development of type 2 diabetes is not currently clear. However, Kahle and colleagues reported that 15 weeks of physical activity at 60-70\% of maximum (i.e., 120-140 bpm), three times per week led to significant reductions in the fasting insulin and glucose levels of obese adolescent males (18). Similarly, four months of exercise training, with a mean heart rate of $157 \mathrm{bpm}$, four times per week led to significant reductions in the fasting insulin levels of obese 7-11 year old children (12). Thus, the data presented here suggest that the strategies implemented in these pilot studies which resulted in students spending more than half of the available class time engaged in MVPA are likely to be an important component of comprehensive strategies to prevent type 2 diabetes.

The strategies implemented in these pilot studies could have potential as part of a future public health policy. For example, providing PE teacher concentrated in-service training to maximize physical activity by improving classroom management skills could be an effective and comparatively inexpensive means of increasing physical activity. More expensive strategies could involve reducing the staff-to-student ratio and provide extra equipment as a means of facilitating small group activities. An extensive evaluation of these components is needed to guide future policy decisions.

\section{Strengths and Limitations}

The strengths of these studies include the testing of a new intervention programs in schools that have a high percentage of students from ethnic groups that are at increased risk of developing type 2 diabetes mellitus, as well as and an objective assessment of physical activity. The sample was obtained at a number of locations across the U.S. which improves the generalizability of the findings. However, monitoring five students heart rates in each class assumes that the activity levels of these students is representative of the entire class. However, the sample was randomly selected and representative of gender, ethnicity and weight status. The study is limited by the absence of baseline data or a control group in both studies, which makes it difficult to determine the additional benefit that the revised program provided. While the use of heart rates to estimate exercise intensity is a strength, it also imposes some weaknesses. Heart rates can be affected by other nonactivity factors such as emotional stress and while any such effect is likely negligible this possible limitation should be recognized. Moreover, while activity during PE classes is more continuous than childhood habitual physical activity which is often sporadic (2), it is possible that, by averaging the heart rate data into minute-long periods, that we masked some of the briefer, higher intensity bursts of activity. It is, however, important to recognize that the data from this study provide useful insights into the development of intervention components, thereby significantly enhancing existing knowledge.

\section{Conclusions}

The heart rate data suggest that PE lessons can be modified to yield increased physical activity. These levels can also be maintained while meeting the curriculum educational guidelines. More than $50 \%$ of the time available in the class can be spent engaged in health enhancing moderate to vigorous intensity physical activity. PE classes can therefore make a substantial contribution to ensuring that children meet physical activity recommendation.

\section{Acknowledgments}

We wish to thank the administration, faculty, staff, students, and their families at the middle schools and school districts that participated in the STOPP-T2D prevention studies. This work was completed with funding from NIDDK/NIH 
grant numbers U01-DK61230, U01-DK61249, U01-DK61231, and U01-DK61223 to the STOPP-T2D collaborative group.

\section{References}

1. Armstrong N, Bray S. Physical activity patterns defined by continuous heart rate monitoring. Arch. Dis. Child 1991;66:245-247. [PubMed: 2001112]

2. Bailey RC, Olson J, Pepper SL, Porszasz J, Barstow TJ, Cooper DM. The level and tempo of children's physical activities: an observational study. Med. Sci. Sports Exerc 1995;27:1033-1041. [PubMed: 7564970]

3. Borghouts LB, Backx K, Mensink MF, Keizer HA. Effect of training intensity on insulin sensitivity as evaluated by insulin tolerance test. Eur. J. Appl. Physiol. Occup. Physiol 1999;80:461-466. [PubMed: 10502080]

4. Dale D, Corbin CB, Dale KS. Restricting opportunities to be active during school time: do children compensate by increasing physical activity levels after school? Res. Q. Exerc. Sport 2000;71:240248. [PubMed: 10999261]

5. Department of Health. P. A.. Health Improvement and Prevention. At least five a week: Evidence of the impact of physical activity and its relationship to health: A report from the Chief Medical Officer. Department of Health, Physical Activity, Health Improvement and Prevention; London: 2004. p. i-vi.

6. Durant RH, Baranowski T, Davis H, et al. Reliability and variability of indicators of heart-rate monitoring in children. Med. Sci. Sports Exerc 1993;25:389-395. [PubMed: 8455456]

7. Dwyer JJ, Allison KR, LeMoine KN, et al. A provincial study of opportunities for school-based physical activity in secondary schools. J. Adolesc. Health 2006;39:80-86. [PubMed: 16781965]

8. Ekelund U, Poortvliet E, Yngve A, Hurtig-Wennlov A, Nilsson A, Sjostrom M. Heart rate as an indicator of the intensity of physical activity in human adolescents. Eur. J. Appl. Physiol 2001;85:244249. [PubMed: 11560077]

9. Epstein LH, Paluch RA, Kalakanis LE, Goldfield GS, Cerny FJ, Rome-mich JN. How much activity do youth get? A quantitative review of heart-rate measured activity. Pediatrics 2001;108:E44. [PubMed: 11533362]

10. Fairclough S, Stratton G. Physical activity levels in middle and high school physical education: A review. Pediatr. Exerc. Sci 2005;17:217-236.

11. Fairclough S, Stratton G. 'Physical education makes you fit and healthy'. Physical education's contribution to young people's physical activity levels. Health Educ. Res 2005;20:14-23. [PubMed: 15253994]

12. Ferguson MA, Gutin B, Le N, et al. Effects of exercise training and its cessation on components of the insulin resistance syndrome in obese children. Int. J. Obes. Relat. Metab. Disord 1999;22:889895. [PubMed: 10490792]

13. Haapanen N, Miilunpalo S, Vuori I, Oja P, Pasanen M. Characteristics of leisure time physical activity associated with decreased risk of premature all cause and cardiovascular disease mortality in middleaged men. Am. J. Epidemiol 1996;143:870-880. [PubMed: 8610700]

14. Hedley AA, Ogden CL, Johnson CL, Carroll MD, Curtin LR, Flegal KM. Prevalence of overweight and obesity among US children, adolescents, and adults, 1999-2002. JAMA 2004;291:2847-2850. [PubMed: 15199035]

15. Hu G, Qiao Q, Silventoinen K, et al. Occupational, commuting, and leisure-time physical activity in relation to risk for Type 2 diabetes in middle-aged Finnish men and women. Diabetologia 2003;46:322-329. [PubMed: 12687329]

16. Jago R, Anderson C, Baranowski T, Watson K. Adolescent patterns of physical activity: Differences by gender, day and time of day. Am. J. Prev. Med 2005;28:447-452. [PubMed: 15894148]

17. Jago R, Baranowski T, Baranowski JC, Thompson D, Greaves KA. BMI from 3-6 y of age is predicted by TV viewing and physical activity, not diet. Int. J. Obes. Relat. Metab. Disord 2005;29:557-564.

18. Kahle EB, Zipf WB, Lamb DR, Horswill CA, Ward KM. Association between mild, routine exercise and improved insulin dynamics and glucose control in obese adolescents. Int. J. Sports Med 1996;17:1-6. [PubMed: 8775568] 
19. Kang HS, Gutin B, Barbeau P, et al. Physical training improves insulin resistance syndrome markers in obese adolescents. Med. Sci. Sports Exerc 2002;34:1920-1927. [PubMed: 12471297]

20. Katzmarzyk PT, Malina RM, Bouchard C. Physical activity, physical fitness, and coronary heart disease risk factors in youth: the Quebec Family Study. Prev. Med 1999;29:555-562. [PubMed: 10600437]

21. Lee IM. Physical activity and cancer prevention-data from epidemiologic studies. Med. Sci. Sports Exerc 2003;35:1823-1827. [PubMed: 14600545]

22. Littell, RC.; Milliken, GA.; Stroup, WW.; Wolfinger, RD. SAS, System for Mixed Models. SAS Institute Inc.; Cary, NC: 1996.

23. McKenzie TL, Catellier DJ, Conway T, et al. Girls' activity levels and lesson contexts in middle school PE: TAAG baseline. Med. Sci. Sports Exerc 2006;38:1229-1235. [PubMed: 16826019]

24. McKenzie TL, Feldman H, Woods SE, et al. Children's activity levels and lesson context during third grade Physical Education. Res. Q. Exerc. Sport 1995;66:184-193. [PubMed: 7481079]

25. McKenzie TL, Sallis JF, Nader PR. SOFIT: system for observing fitness instruction time. J Teach Phys Educ 1991;11:195-205.

26. McKenzie TL, Sallis JF, Prochaska JJ, Conway TL, Marshall SJ, Rosengard P. Evaluation of a twoyear middle school physical education intervention: MSPAN. Med. Sci. Sports Exerc 2004;36:13821388. [PubMed: 15292747]

27. McMurray RG, Bauman MJ, Harrell JS, Brown S, Bangdiwala SI. Effects of improvement in aerobic power on resting insulin and glucose concentrations in children. Eur. J. Appl. Physiol 2000;81:132139. [PubMed: 10552278]

28. Rosengard, P.; Mckenzie, TL. Spark physical education program grades 6-8. San Diego State University Foundation; San Diego: 2001.

29. Sallis JF, McKenzie TL, Alcaraz JE, Kolody B, Faucette N, Hovell MF. The effects of a 2 year physical education program (SPARK) on physical activity and fitness in elementary school students. Sports, Play and Active Recreation for Kids. Am. J. Public Health 1997;87:132-1334.

30. Strong WB, Malina RM, Blimkie CJ, et al. Evidence based physical activity for school-age youth. J. Pediatr 2005;146:732-737. [PubMed: 15973308]

31. U.S. Department of Health and Human Services. Healthy people 2010: Understanding and improving health. U.S. Department of Health and Human Services; Washington, DC: 2000. p. B22-B16.

32. Surgeon General, U.S.. US Surgeon General's report on physical activity and health. US Department of Health and Human Services \& Centers for Disease Control and Prevention; 1996. p. 1-9.

33. van Beurden E, Barnett LM, Zask A, Dietrich UC, Brooks LO, Beard J. Can we skill and activate children through primary school physical education lessons? "Move it Groove it" - a collaborative health promotion intervention. Prev. Med 2003;36:493-501. [PubMed: 12649058] 
Table 1

Mean (SD) Indicators of Physical Activity in the PE Classes Presented by Week of Intervention for Activity-Based Study

\begin{tabular}{llcc}
\hline Week & Mean HR (bpm) & $\begin{array}{c}\text { Minutes of MVPA (130 bpm) } \\
\mathbf{2}\end{array}$ & $\begin{array}{c}\text { Minutes of MVPA (140 bpm) } \\
\mathbf{3} \text { as \% of time wearing HRM }\end{array}$ \\
\hline $1(n=276)$ & $144.15(16.43)$ & $65.95(22.76)$ & $54.97(23.83)$ \\
$2(n=378)$ & $143.21(15.55)$ & $66.89(20.58)$ & $55.56(22.34)$ \\
$3(n=313)$ & $145.17(15.00)$ & $68.85(19.52)$ & $57.96(22.62)$ \\
$4(n=236)$ & $146.57(16.84)$ & $71.17(22.99)$ & $59.37(26.31)$ \\
$5(n=193)$ & $150.08(17.10)$ & $76.12(23.87)$ & $66.18(27.96)$ \\
$6(n=248)$ & $147.35(16.98)$ & $72.88(22.86)$ & $60.06(27.18)$ \\
$7(n=83)$ & $150.34(15.11)$ & $75.56(18.01)$ & $64.22(21.48)$ \\
\hline
\end{tabular}

${ }^{1}$ Each day of the intervention increased mean HR by an average of $0.19 \mathrm{bpm}(95 \% \mathrm{CI} 0.12-0.26)$.

2 Each day of the intervention increased percent MVPA by 0.31 percentage points (95\% CI 0.19-0.42).

3 Each day of the intervention increased percent MVPA by 0.34 percentage points ( $95 \%$ CI $0.24-0.44$ ). 


\section{Table 2}

Descriptive Information for Curriculum-Based Study Participants

\begin{tabular}{|c|c|c|c|c|}
\hline & $\mathbf{N}$ & & Median & \\
\hline Age (yrs) & 1,544 & & 11 & \\
\hline \multirow[t]{2}{*}{$\operatorname{BMI}\left(\mathrm{kg} / \mathrm{m}^{2}\right)$} & 1,542 & & 20.65 & \\
\hline & \multicolumn{3}{|c|}{$\mathbf{N}$} & Percent \\
\hline Male & \multicolumn{3}{|c|}{791} & 51.23 \\
\hline Female & \multicolumn{3}{|c|}{753} & 48.77 \\
\hline Missing & \multicolumn{3}{|c|}{3} & \\
\hline BMI $<85 \%$ tile & \multicolumn{3}{|c|}{839} & 54.41 \\
\hline BMI $>85$ th $\%$ tile & \multicolumn{3}{|c|}{703} & 45.59 \\
\hline Missing & \multicolumn{3}{|c|}{5} & \\
\hline Asian & \multicolumn{3}{|c|}{23} & 1.49 \\
\hline Black & \multicolumn{3}{|c|}{413} & 26.70 \\
\hline Hispanic & \multicolumn{3}{|c|}{794} & 51.33 \\
\hline Native American & \multicolumn{3}{|c|}{14} & 0.90 \\
\hline Pacific Islander & \multicolumn{3}{|c|}{3} & 0.19 \\
\hline White & \multicolumn{3}{|c|}{192} & 12.41 \\
\hline Other & \multicolumn{3}{|c|}{108} & 6.98 \\
\hline
\end{tabular}


Table 3

Mean (SD) Indicators of Physical Activity in the PE Classes Presented by Week of Intervention for Curriculum-Based Study

\begin{tabular}{llcc}
\hline Week & Mean HR (bpm) & $\begin{array}{c}\text { Minutes of MVPA as \% of } \\
\text { time wearing as HRM }(\mathbf{1 3 0} \\
\text { bpm) }\end{array}$ & $\begin{array}{c}\text { Minutes of MVPA as \% of } \\
\text { time wearing HRM (140 } \\
\text { bpm) }\end{array}$ \\
\hline $1(n=150)$ & $145.69(13.31)$ & $71.78(20.93)$ & $58.32(22.61)$ \\
$2(n=206)$ & $142.05(17.50)$ & $65.65(23.91)$ & $51.49(25.26)$ \\
$3(n=212)$ & $140.40(15.75)$ & $63.45(25.22)$ & $49.07(27.23)$ \\
$4(n=201)$ & $141.85(14.85)$ & $65.98(23.68)$ & $52.47(25.89)$ \\
$5(n=226)$ & $141.12(16.17)$ & $64.09(25.84)$ & $50.58(27.58)$ \\
$6(n=183)$ & $142.84(14.10)$ & $67.83(23.02)$ & $53.23(24.47)$ \\
$7(n=157)$ & $144.22(16.13)$ & $68.18(23.95)$ & $55.30(25.03)$ \\
$8(n=177)$ & $145.96(14.85)$ & $72.25(23.28)$ & $57.86(24.19)$ \\
$9(n=35)$ & $143.60(18.48)$ & $67.34(26.58)$ & $54.77(27.15)$ \\
\hline
\end{tabular}

$(95 \% \mathrm{CI}=-9.6$ to $-0.3, p<.001)$. There were no significant differences between the normal-weight (BMI $>85$ th percentile) or at risk for overweight (BMI $\geq 85$ th percentile) groups $(p>.05)$ and there were no differences $(p>.05)$ by ethnicity (data not shown). 
Table 4

Mean (SD) of Physical Activity in the PE Classes Presented by Week of Intervention for Curriculum-Based Study by Gender

\begin{tabular}{|c|c|c|c|c|}
\hline \multicolumn{5}{|c|}{ Female } \\
\hline WK & $\mathbf{n}$ & Mean BPM & $\begin{array}{c}\text { \% MVPA (130 bpm) of HR } \\
\text { time }\end{array}$ & $\begin{array}{c}\text { \% MVPA (140 bpm) of } \\
\text { HR time }\end{array}$ \\
\hline 1 & 73 & $143.48(10.80)$ & $69.48(18.56)$ & $54.15(19.61)$ \\
\hline 2 & 102 & $140.01(13.75)$ & $64.00(24.19)$ & $47.75(25.05)$ \\
\hline 3 & 99 & $137.75(14.37)$ & $59.76(25.38)$ & 43.57 (26.44) \\
\hline 4 & 97 & $138.35(15.02)$ & $61.70(24.89)$ & $47.20(26.56)$ \\
\hline 5 & 120 & $136.42(15.88)$ & $57.46(26.25)$ & $42.24(29.96)$ \\
\hline 6 & 101 & $141.63(13.81)$ & $67.35(23.61)$ & $51.38(24.85)$ \\
\hline 7 & 76 & $143.59(15.00)$ & $67.39(23.03)$ & $53.27(25.02)$ \\
\hline 8 & 75 & $142.92(15.74)$ & $68.66(25.58)$ & $54.04(26.54)$ \\
\hline 9 & 10 & $144.61(7.89)$ & $76.55(17.21)$ & $58.77(22.25)$ \\
\hline \multicolumn{5}{|c|}{ Male } \\
\hline WK & $\mathbf{n}$ & Mean BPM & $\begin{array}{c}\text { \% MVPA (130 bpm) of HR } \\
\text { time }\end{array}$ & $\begin{array}{c}\text { \% MVPA (140 bpm) of } \\
\text { HR time }\end{array}$ \\
\hline 1 & 77 & $147.78(15.08)$ & $73.96(22.86)$ & $62.28(24.60)$ \\
\hline 2 & 104 & $144.04(15.92)$ & $67.28(23.64)$ & $55.17(25.05)$ \\
\hline 3 & 113 & $142.71(16.60)$ & $66.68(24.74)$ & $53.89(27.10)$ \\
\hline 4 & 103 & $144.90(13.87)$ & $69.70(21.78)$ & $56.99(24.14)$ \\
\hline 5 & 106 & $146.45(14.86)$ & $71.60(23.28)$ & $60.03(25.24)$ \\
\hline 6 & 82 & $144.34(14.39)$ & $68.41(22.40)$ & $55.50(23.95)$ \\
\hline 7 & 81 & $144.81(17.20)$ & $68.92(24.89)$ & $57.20(25.05)$ \\
\hline 8 & 100 & $148.05(13.93)$ & $74.49(21.21)$ & $60.42(22.15)$ \\
\hline 9 & 25 & $143.19(21.44)$ & $63.66(28.98)$ & $53.17(29.15)$ \\
\hline
\end{tabular}

